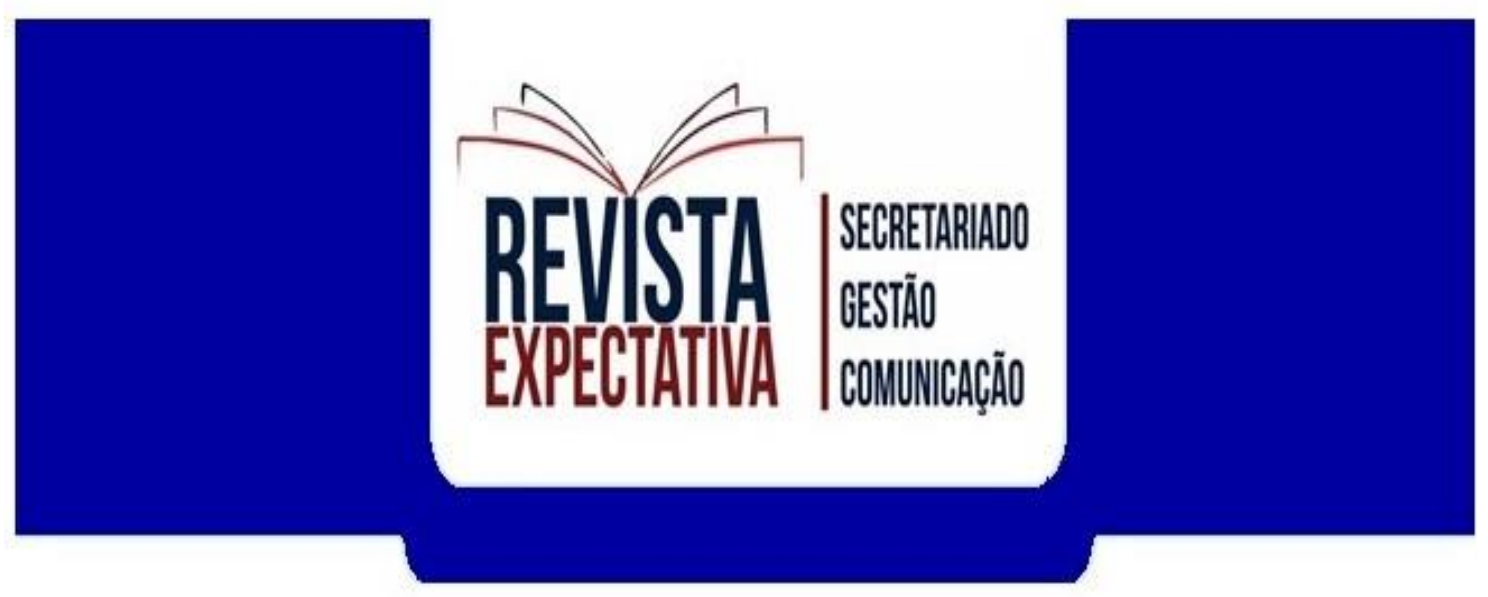

\title{
Um estudo do desenvolvimento de capacitação para cargos secretariais em uma Universidade Estadual
}

\author{
Lygia de Souza Moraes ${ }^{1}$, Juliana Hortelã Pedrone Valério², Aline Cantarotti ${ }^{3}$
}

Resumo: A atuação no serviço público ainda é muito atrativa em virtude de benefícios que a iniciativa privada não proporciona. O presente estudo é de caráter intervencionista e pretende investigar as deficiências dos servidores técnicos de nível médio que atuam nas secretarias de uma universidade do estado do Paraná e propor capacitação para sanar tais deficiências. Para isso, foi aplicado um questionário a fim de identificar quais as maiores dificuldades enfrentadas por eles, e quais seriam passíveis de serem ensinadas em cursos de curta duração. Foi utilizada a pesquisa de campo, de abordagem qualitativa, quantitativa e de observação participante. O referencial teórico aborda a gestão pública, a gestão de pessoas, a gestão e o assessoramento secretarial e as habilidades secretariais no serviço público. Pode-se apurar que as observações a partir do questionário aplicado têm fundamento no que tange aos problemas apresentados pelos servidores considerando a dificuldade na realização das suas tarefas e atendimento ao público, e que a aplicabilidade deste estudo é viável por meio da utilização de pessoal disponível no curso de Secretariado Executivo Trilíngue da mesma instituição.

\footnotetext{
${ }^{1}$ Bacharel em Secretariado Executivo Trilíngue, com habilitação em Francês/Espanhol, pela Universidade Estadual de Maringá. Mestranda em Políticas Públicas pela mesma instituição. Atualmente é auxiliar administrativo da Universidade Estadual de Maringá. https://orcid.org/0000-0002-8371-7765

2 Doutoranda e Mestre em Letras/ Linguística - Linha de pesquisa Texto e Discurso da Universidade Estadual de Maringá. Bacharel em Secretariado Executivo Trilíngue pela UNESPAR-FECEA - Faculdade de Ciências Econômicas de Apucarana (2007). Especialista em "Gestão Estratégica de Empresas" (2010), e também "Docência no Ensino Superior"(2012), ambas pelo Instituto Paranaense de Ensino. https://orcid.org/0000-0002-3977-2150

${ }^{3}$ Doutorado em Estudos Linguísticos pela Universidade Estadual Paulista Júlio de Mesquita Filho, Brasil (2018). Professora da UEM -Universidade Estadual de Maringá. https://orcid.org/0000-0003-1034-6825
}

Editor: Cezar Roberto Versa

Recebido em: 17/01/2020 - Revisado em: 15/04/2020 - Aprovado em: 21/06/2020

Revista Expectativa- e-ISSN 1982-3029 - v.19 - n.1 - jan./jun. - 2020 
Palavras-chave: Gestão de Pessoas. Capacitação no serviço público. Habilidades secretariais.

\begin{abstract}
The performance in the public service is still very attractive due to the benefits that the private initiative does not provide. The present study is interventionist considering its nature and intends to investigate the deficiencies of the technical servants who work in the secretariats of a university in the state of Paraná and propose training to remedy such deficiencies. In order to achieve this goal, a questionnaire was applied to identify which are the biggest difficulties faced by these workers, and which ones could be taught in short courses. Field research was used, with a qualitative-quantitative approach and participant observation. The theoretical framework addresses public management, human resources management, secretarial management and advisory and secretarial skills in the public service. It can be verified that the observations from the applied questionnaire are based on the problems presented by the servers considering the difficulty in performing their tasks and serving the public, and that the applicability of this study is feasible through the use of available personnel in the Trilingual Executive Secretariat undergraduate course at the same institution.
\end{abstract}

Keywords: Human Resources Management. Training in public service. Secretarial skills.

\title{
1 INTRODUÇÃO
}

No Brasil, o exercício do serviço público é atrativo, seja pela estabilidade, seja pelos salários. Entretanto, o que já foi visto como função de alto status na sociedade, hoje, em alguns casos, pode ser considerado uma garantia de proventos, de trabalho, não necessitando, geralmente, de grande desenvolvimento profissional aprofundado para manutenção do cargo.

No entanto, nos últimos anos, além das políticas públicas que visam enxugar a máquina governamental, optando muitas vezes pela terceirização, tem diminuído consideravelmente a abertura de concursos públicos em todas as esferas do governo. O mesmo ocorre com maior ênfase quanto a contratação de técnico-administrativos, na instituição escolhida para a 
pesquisa.

Deste modo, pretende-se neste trabalho realizar um estudo com foco nos servidores de nível médio, atuantes em serviços secretariais, que têm sofrido com a falta de reposição de pessoal. Esse cenário é agravado pelo fato de que as políticas públicas, por parte do governo do Estado, têm sido de reduzir as contratações de servidores efetivos, optando pela contratação de pessoal temporário. Isso tem fragilizado de modo demasiado o atendimento nos mais diversos setores da Universidade. Há vários casos de departamentos onde não existe nenhum servidor efetivo, e nem mesmo o servidor na modalidade "temporário".

Além disso, e em virtude dessa política, a rotatividade de funcionários se faz presente, fato que agrava ainda mais a necessidade de capacitação de modo mais padronizado dos servidores que atendem ao público e trabalham nos setores de secretaria.

Como uma parcela dos servidores que trabalham nesses setores são técnico-administrativos de nível médio, não lhe são exigidos o diploma universitário, apesar dos benefícios salariais que este poderia the trazer. A qualificação na área de secretariado é ainda menos vigente, já que a formação nessa área propiciaria um desenvolvimento das habilidades mais necessárias para o exercício da função. É importante ressaltar que estamos falando de recursos humanos com alguns anos exercendo tais funções, estando enquadrados na carreira de servidores já também estabelecida de longa data na instituição.

A Universidade costuma oferecer cursos de qualificação a seus servidores, por meio da divisão de Treinamento e Desenvolvimento (TDE), vinculada à Pró-Reitoria de Recursos Humanos e Assuntos Comunitários $(\mathrm{PRH})$. Entretanto, comumente a procura por cursos junto a esta divisão se dá em razão de que esta participação promove a progressão de níveis na carreira do servidor e, com isso, o aumento em seus salários. Assim, eles estão geralmente interessados na carga horária fornecida pelo curso e não em seu conteúdo, problema para o qual o desenvolvimento desta pesquisa poderia, em um outro momento, também beneficiar os servidores e a instituição ao, possivelmente, alterar essa visão. 
Para o presente estudo, o foco é a identificação das dificuldades dos servidores no desenvolvimento do trabalho diário, a fim de procurar saná-las com a elaboração de cursos que desenvolvam as habilidades secretariais em servidores técnico-administrativos de nível médio que atuem em secretarias na instituição de ensino pesquisada. O tema foi escolhido por uma das pesquisadoras atuar nesta instituição há aproximadamente 14 anos e por estar cursando Secretariado Executivo Trilíngue na mesma Universidade. Observouse a carência de habilidades nos servidores com os quais houve contato.

Dessa forma também se propagariam os conhecimentos adquiridos no curso de Secretariado Executivo Trilíngue aos servidores técnicoadministrativos de nível médio da instituição, tendo como meta a melhoria na qualidade do trabalho dos servidores que atuam nas secretarias da Universidade. Percebe-se que esse problema pode ser gerado pela rotina estabelecida por servidores com muitos anos de carreira, que geralmente não se atualizam e acabam exercendo uma cogestão desqualificada quanto aos novos funcionários públicos em treinamento, o que acarreta também a alta rotatividade de pessoal temporário, e o seu baixo entendimento dos processos.

Este trabalho foi dividido em quatro partes, além desta introdução. Em seguida, temos um estudo bibliográfico dividido em quatro seções: gestão pública, gestão de pessoas, gestão e assessoramento secretarial e habilidades secretariais no serviço público. Na sequência, apresentamos os procedimentos metodológicos utilizados na pesquisa. No quarto capítulo, temos a análise dos resultados apurados e as discussões, seguidas das considerações finais.

\section{REFERENCIAL TEÓRICO}

O referencial teórico deste trabalho será organizado em quatro partes: 1) gestão pública; 2) gestão de pessoas; 3) gestão e assessoramento secretarial; e 4) habilidades secretariais no serviço público.

\subsection{GESTÃO PÚBLICA}


Entre os anos 1970 e 1980 ocorreu uma crise que se estendeu ao Estado, numa conjuntura de inflação em alta contínua, impactando nos investimentos na máquina pública. Assim, no governo do Presidente Fernando Henrique Cardoso, foi criada a Câmara da Reforma do Estado, a quem coube elaborar o Plano Diretor da Reforma do Aparelho do Estado, que procurou estabelecer parâmetros para uma transição programada de um tipo de administração pública burocrática, rígida e ineficiente, para uma administração pública gerencial, flexível e eficiente, voltada para o atendimento ao cidadão. Esse plano era apoiado, ainda que flexibilizado, em alguns dos princípios fundamentais da administração pública burocrática, como a admissão segundo rígidos critérios de mérito, um sistema estruturado de carreira e remuneração, a avaliação constante de desempenho e o treinamento sistemático. (BRASIL, 1995).

Este plano dividia o aparelho do Estado em quatro setores: núcleo estratégico, atividades exclusivas, serviços não exclusivos e produção de bens e serviços para o mercado. A aplicação desse plano seria verticalizada, começando pelo âmbito federal e se estendendo para os estados e, posteriormente, aos municípios. As universidades públicas, sendo objeto de pesquisa do presente estudo, são enquadradas como serviços não exclusivos, para as quais, entre outros, foram estabelecidos os objetivos de serem transferidos para o setor público não estatal, como entidades sem fins lucrativos, com poder de gerenciamento próprio, inclusive com direito à dotação orçamentária, o que conferiria autonomia a seus dirigentes e assim, aumentar a eficiência e a qualidade dos serviços, atendendo melhor o cidadão-cliente a um custo menor. (BRASIL, 1995).

Essa proposta de aproximar a administração pública da privada ficou conhecida como Nova Administração Pública. Entretanto, esse modelo apresenta dificuldades no setor público, já que a facilidade de se adequar aos cenários atuais é mais difícil para tal setor que necessita de consenso político e alteração de leis. Assim, tornar presente a eficiência do setor privado no público com êxito imediato resultou, em grande parte, em mera ilusão, em todas as esferas tanto quanto no que tange à gestão de pessoas (MOTTA, 
2013).

\subsection{GESTÃO DE PESSOAS}

As organizações têm, cada vez mais, dado importância para a gestão de recursos humanos, área da administração que se ocupava com rotinas diretamente ligadas com o pessoal das organizações, como recrutamento e seleção e folha de pagamento, por exemplo. Com o passar do tempo, outras rotinas foram incorporadas a esta unidade administrativa, como o treinamento, não só pontual bem como continuado, processos de avaliação, além de outros que tornaram a melhoria da qualidade de vida dos colaboradores uma meta permanente. Surge então a Gestão de Pessoas, que para Chiavenato (2004, p. 577), é o "conjunto de políticas e práticas necessárias para conduzir os aspectos da posição gerencial relacionados com pessoas ou recursos humanos, incluindo recrutamento, seleção, treinamento, recompensas e avaliação do desempenho". Assim, é cada vez mais comum ver esse tipo de política aplicada à administração das mais diversas instituições, do setor privado ao público, já que ela reflete a cultura da organização, além de outros fatores como estrutura organizacional, processos internos, entre outros (BRUNELLI, 2008).

No caso do setor público, esse avanço é mais lento, visto que muitas instituições ainda buscam por atualizações tecnológicas, e ainda predominam a execução de trabalho burocrático e operacional (AMARAL; LOPES, 2014).

O Departamento de Aspectos Econômicos e Sociais da ONU (2006, p.389) afirma que os governos devem "desenvolver uma estratégia de Gestão de Recursos Humanos fundamentada em três escolas ou modelos de administração pública: a administração pública tradicional; a gestão pública, incluindo a Nova Gestão Pública; e a governança responsiva".

Amaral e Lopes (2014), a partir da citação acima, discorrem explanando que a Administração Pública tradicional se mantém sustentada na imparcialidade e na meritocracia, enquanto o modelo de Gestão Pública tem suas peculiaridades sustentadas na gestão por desempenho e por resultados. 
Já a escola de governança traz à tona novas abordagens que objetivam tornar a administração pública mais responsável frente à demanda dos cidadãos (AMARAL; LOPES, 2014).

\subsubsection{Gestão de Pessoas no Serviço Público}

A Gestão de Pessoas no serviço público, de acordo com Bergue (2007), tem como foco o suprimento, a manutenção e o desenvolvimento de pessoas nas organizações públicas, observadas as necessidades e condições do ambiente em que se inserem. Ele também acrescenta que, na visão do servidor público, a gestão da carreira é mensurada pelo ciclo de tempo em que ele poderá solicitar a ascensão de níveis, e com isso o aumento de seus ganhos (BERGUE, 2007).

A partir desses conceitos, têm-se a ideia de que é necessário melhorar o desempenho dos setores públicos no país, e que uma forma possível de alcançar esse objetivo se dá pela melhoria do serviço prestado por seus trabalhadores, o que geralmente fica a cargo dos setores de Treinamento e Desenvolvimento de cada instituição, ou qualquer outro equivalente.

Amorim e Silva (2012) lembram que não se pode prescindir de treinamento no serviço público, visto que a forma de ingresso desses servidores é realizada por meio de concurso público, em que são exigidos dos candidatos, geralmente, apenas conhecimentos teóricos. O aprendizado do servidor ocorre durante o estágio probatório, momento em que também se conhece suas habilidades, e até inabilidades, comportamentais (CORREA apud AMORIM E SILVA, 2012).

Como, a partir dos conceitos citados, melhorar a capacidade de trabalho de servidores dos quais não são exigidas habilidades específicas durante o seu processo de seleção é o desafio a ser enfrentado. Amorim e Silva (2012, p. 6) afirmam que "o treinamento é um meio usado pelas organizações que desejam manter seu quadro de funcionários preparado para as demandas ambientais e também um aliado para a motivação".

Considerando a natureza dos serviços executados pela maioria dos servidores de nível médio atuantes nas secretarias dos departamentos de uma 
universidade pública, foco do presente estudo, esse treinamento seria melhor aproveitado por meio do desenvolvimento das habilidades secretariais desses trabalhadores, especificamente na área de gestão secretarial, visto o profissional de secretariado ser polivalente e fundamental nas organizações. (LESSA; SCHELL, 2015).

\subsection{GESTÃO E ASSESSORAMENTO SECRETARIAL}

As funções de gestão são desempenhadas em várias profissões, apesar de advir de uma função da administração. Ferreira, Reis e Pereira (2002, p. 6), afirmam que:

\footnotetext{
todo indivíduo que desempenha uma função gerencial exerce funções típicas do administrador, independentemente da sua formação técnica e profissional em qualquer área de conhecimento (engenharia, direito, economia, agronomia, medicina, informática etc.).
}

Assim sendo, esse conceito é ainda mais natural à área do secretariado, ligada de forma mais íntima à Administração, tendo inclusive estudos dedicados especificamente a esse aspecto, a Gestão Secretarial, que pode ser designado pelo modo mais gerencial de secretariar, estando 0 profissional de Secretariado em uma posição um pouco mais elevada, de assessor para gestor (DURANTE e FÁVERO apud SILVA, BARROS e BARBOSA, 2012).

Não importa qual seja a área de atuação do profissional de secretariado, ele é prioritariamente um assessor, aquele que interliga realidades, pessoas e conhecimentos, atuando nos mais diversos níveis hierárquicos. Nonato Junior caracteriza a ciência da assessoria em quatro eixos básicos, e define o assessoramento como o trabalho direto do secretário, o conhecimento produzido pela aplicação das técnicas secretariais, ou seja, a utilização das ferramentas na rotina e a execução das atividades diárias (NONATO JUNIOR, 2009). 


\subsection{HABILIDADES SECRETARIAIS NO SERVIÇO PÚBLICO}

Para o presente estudo, após levantamento bibliográfico e estudo de campo, definimos que o ensino das técnicas de assessoramento se aplica em cursos de capacitação, ou seja, na busca pelo desenvolvimento das técnicas secretariais aos servidores que pretendem melhorar a eficiência e a eficácia do seu trabalho.

Necessitamos, então, definir quais habilidades seriam passíveis de serem aplicadas em treinamentos, que geralmente são cursos de curta duração, sempre pregando por um método eficaz de aperfeiçoamento.

A Resolução Conjunta no 001/2007-SEAP/SETI, definiu o perfil profissiográfico das funções a serem exercidas no serviço público do Estado do Paraná. Para o técnico administrativo de nível médio, são elencadas as seguintes tarefas que compõem a Função:

1. Realizar trabalhos administrativos da Instituição nas áreas de recursos humanos, finanças, acadêmicas, logística e de administração geral.

2. Atender ao público interno e externo.

3. Fazer e atender chamadas telefônicas obtendo e fornecendo informações.

4. Preparar relatórios e planilhas de cálculos diversos.

5. Elaborar documentos administrativos, tais como oficio, informação ou parecer técnico, memorandos, atas etc.

6 . Secretariar as unidades.

7. Orientar, instruir e proceder a tramitação de processos, orçamentos, contratos e demais assuntos administrativos.

8. Elaborar levantamentos de dados e informações.

9. Participar de projetos na área administrativa ou outra.

10. Participar de comissões e grupos de trabalhos, quando designado.

11. Efetuar registro, preenchimento de fichas, cadastro, formulários, requisições de materiais, quadros e outros similares.

12. Elaborar, sob orientação, planos iniciais de organização, gráficos, fichas, roteiros, manuais de serviços, boletins e formulários.

13. Elaborar estudos objetivando o aprimoramento de normas e métodos de trabalho.

14. Proceder as operações micrográficas, seguindo normas técnicas.

15. Arquivar sistematicamente documentos e microfilmes.

16. Manter organizado e ou atualizar arquivos, fichários e outros, promovendo medidas de preservação do patrimônio documental.

17. Auxiliar na organização de promoções culturais e outras.

18. Receber, conferir, armazenar, controlar e entregar produtos, materiais e equipamentos no almoxarifado ou em outro local.

19. Auxiliar na manipulação de medicamentos, sob supervisão.

20. Participar de programa de treinamento, quando convocado.

21. Zelar pela conservação, limpeza e manutenção dos equipamentos e ambiente de trabalho. 
22. Executar tarefas pertinentes à área de atuação, utilizando-se de equipamentos e programas de informática.

23. Executar outras tarefas compatíveis com as exigências para o exercício da função.

Dentre as competências inerentes às funções de assessoramento, se destacam, no enquadramento de um técnico nível médio que atua em secretarias de departamentos da universidade, as seguintes atribuições:

- atendimento ao público e ao superior, presencialmente ou por telefone;

- gestão documental (física e digital);

- elaboração e redação de documentação oficial, incluindo as de reuniões;

- organização de eventos. (SCHUMACHER; PORTELA; BORTH, 2013).

Como listado, apesar das especificidades do serviço público, no que concerne às rotinas burocráticas, as atividades realizadas estão diretamente relacionadas com as habilidades que deve desenvolver no perfil profissiográfico do profissional de secretariado, seja este técnico, tecnólogo ou bacharel. Assim, como veremos adiante, capacitar os servidores de nível médio, após um diagnóstico de suas insuficiências, pode ser um caminho eficiente e eficaz para o desenvolvimento efetivo das atividades desempenhadas pelos profissionais que ocupam esses cargos.

\section{PROCEDIMENTOS METODOLÓGICOS}

A pesquisa científica é utilizada para, através do uso de métodos prédefinidos, descobrir respostas e soluções para problemas de assuntos diversos. Entretanto, para cada tipo de problema existe um método que se adapta melhor para a busca das soluções. No presente trabalho, a pesquisa tem uma abordagem qualitativa pois parte da coleta de dados para levantamento das dificuldades, além de elaborar um diagnóstico dos dados apurados. É também participante, já que uma das pesquisadoras também se insere no universo estudado.

De acordo com Terence e Escrivão Filho (2006), na abordagem qualitativa, o pesquisador procura

[...] aprofundar-se na compreensão dos fenômenos que estuda ações dos indivíduos, grupos ou organizações em seu ambiente e contexto social - interpretando-os segundo a perspectiva dos participantes da situação enfocada [...]. Assim sendo, a interpretação, 
a consideração do pesquisador como principal instrumento de investigação e a necessidade do pesquisador de estar em contato direto e prolongado com o campo, para captar os significados dos comportamentos observados, revelam-se como características da pesquisa qualitativa. (p.2-3).

A pesquisa participante é aquela na qual o pesquisador se envolve nas atividades a fim de observar os fenômenos e compartilhar a vivência, participando de forma sistemática e permanente, ao longo do tempo de pesquisa. (SEVERINO, 2012)

Para isso, aplicando-se os métodos mencionados, procurou-se verificar as maiores carências no exercício da função mediante a pesquisa junto aos servidores, por meio da aplicação de questionário enviados por e-mail, utilizando-se da plataforma digital de elaboração de questionários SurveyMonkey, em sua versão gratuita. No questionário, o servidor pode apontar as maiores dificuldades que encontra no desenvolvimento de seu trabalho, proporcionando assim, dados que permitirão, com base na bibliografia adequada, elaborar e programar cursos de qualificação a serem ofertados pela Divisão de Treinamento e Desenvolvimento da UEM.

\section{ANÁLISES E DISCUSSÕES DOS RESULTADOS}

O questionário elaborado para identificação das dificuldades ficou disponível para acesso entre os dias 10 e 17 de abril de 2017. Foram ao todo 84 respondentes, sendo $54,76 \%$ do sexo feminino e $45,24 \%$ do sexo masculino, o que diverge um pouco do cenário comumente apresentado na profissão de secretariado, com os cargos sendo ocupados, majoritariamente pelo, sexo feminino, o que pode ser fruto da forma de ingresso.

Quanto à idade e tipo de vínculo dos servidores, podemos observar na figura 1, que dos 84 respondentes, 38 tem acima de 46 anos (45,24\%). Isso pode decorrer em virtude de que nas últimas duas décadas foram realizados poucos concursos para técnicos-administrativos e que por isso o número de jovens servidores tende a ser baixo entre os efetivos, que foram ampla maioria entre os respondentes. 
Figura 1 - Distribuição dos respondentes por idade e por tipo de vínculo

Idade

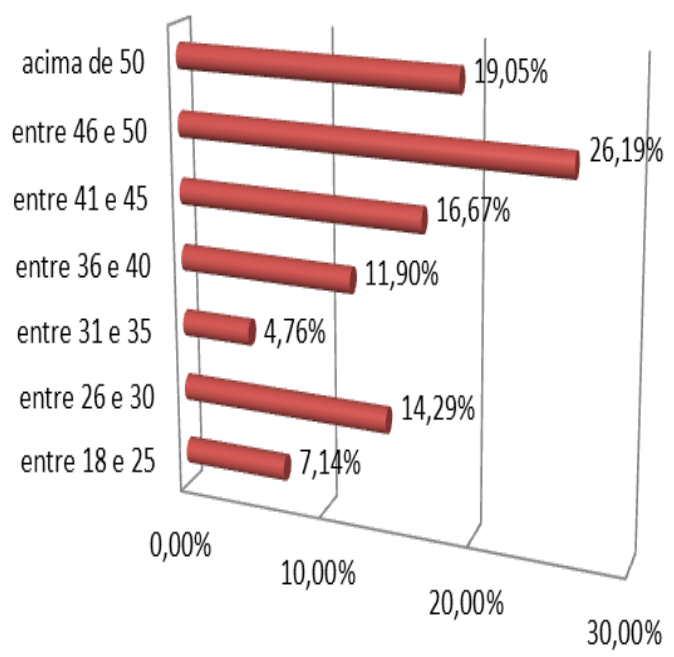

Efetivo ou temporário

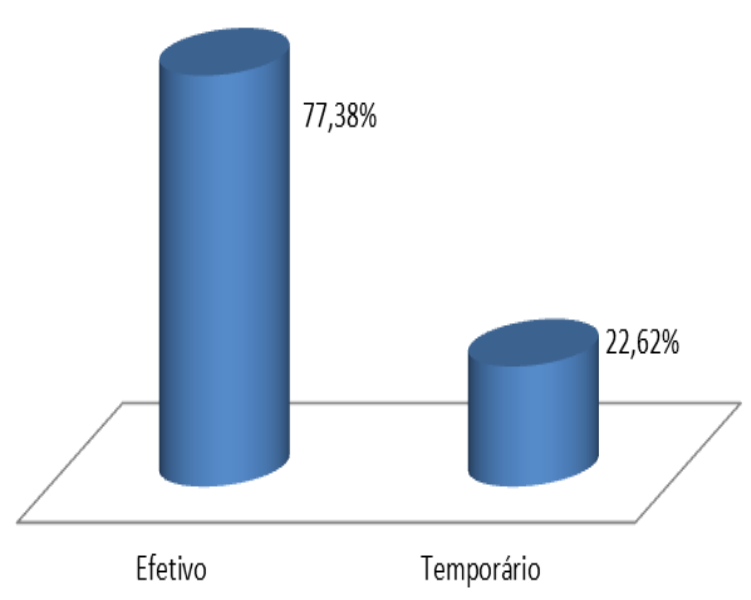

Fonte: Dados da pesquisa.

Podemos observar na figura 2 que $88,09 \%$ dos respondentes tem nível superior ou pós-graduação nas modalidades lato e stricto sensu (identificados na opção "outro", o que não é exigido para a função. Entretanto, o título é buscado, independentemente da área em que o servidor atua, pois concede aumento salarial com a progressão de classe na carreira de técnico administrativo de nível médio.

Figura 2 - Distribuição dos respondentes por escolaridade 


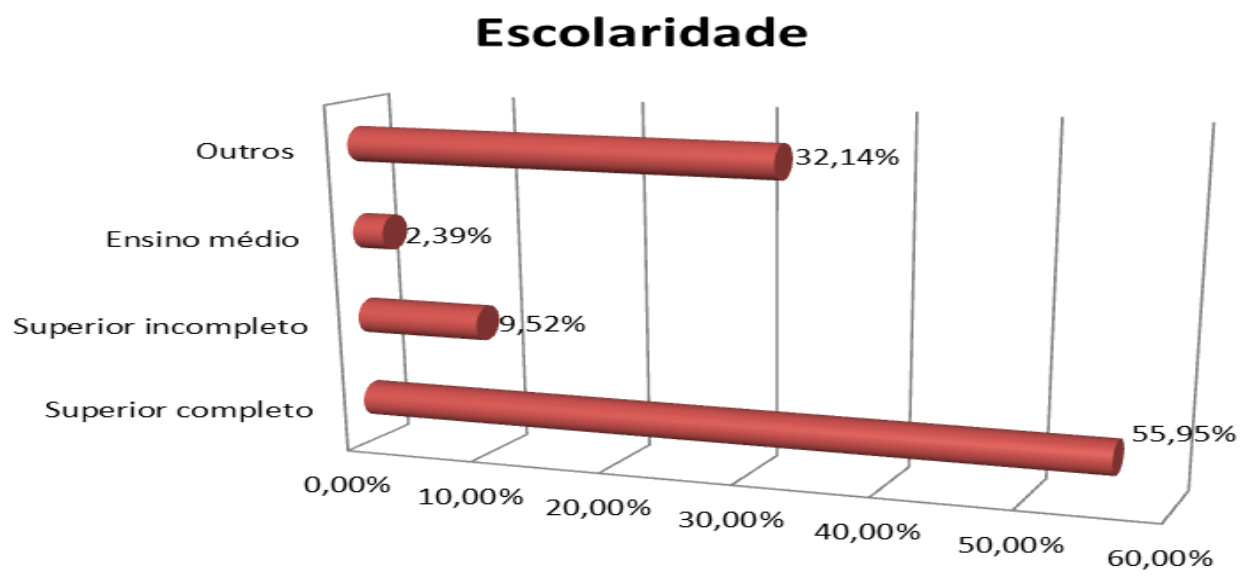

Fonte: Dados da pesquisa.

Ao analisar a figura 3, podemos observar que mais da metade dos servidores que responderam $(51,19 \%)$ atuam na universidade por mais de 16 anos. Portanto, são servidores com experiência na função e conhecimento dos trâmites e dos órgãos da universidade, ou seja, devem saber do funcionamento e burocracia da rotina de trabalho, e que no que tange ao trabalho em departamentos que exigem trabalho secretarial, $57,14 \%$ dos servidores atuam nesta função há mais de 10 anos.

Figura 3 - Tempo de trabalho na instituição e tempo de atuação em funções secretariais

\section{Tempo de atuação na universidade}

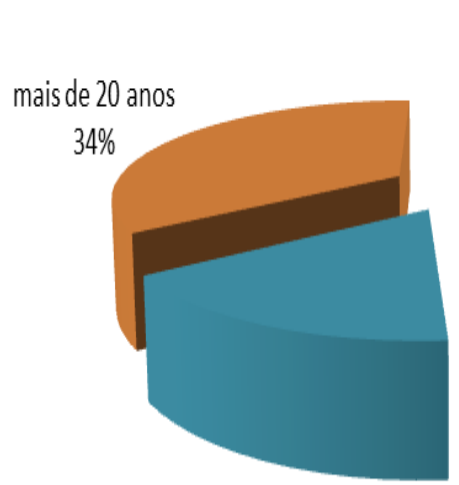

de 16 a 20 anos

$17 \%$

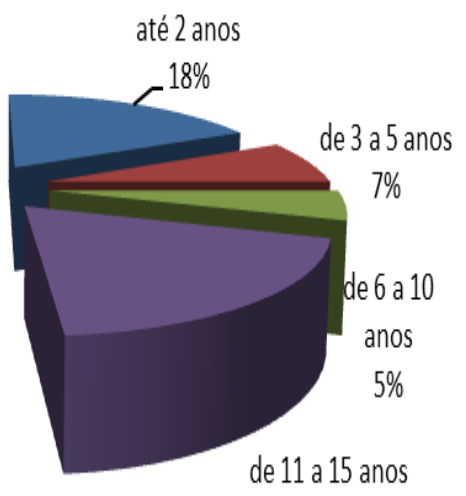

$19 \%$

\section{Atuação em funções secretariais}

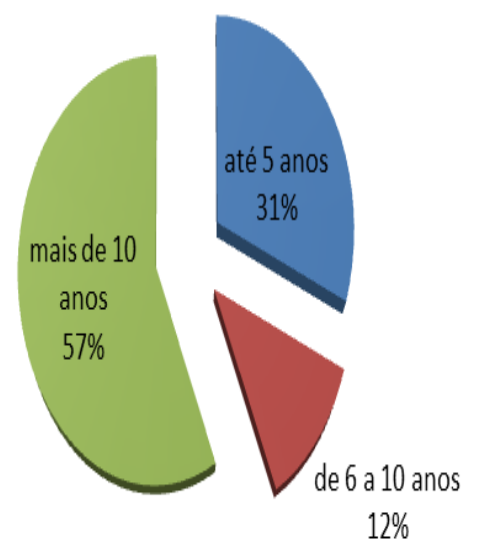

$12 \%$ 
Fonte: Dados da pesquisa.

Devemos, mais uma vez, ressaltar que os dados podem expressar 0 contexto das políticas públicas do Estado do Paraná para a Educação, que não tem autorizado a abertura de concurso público e/ou a contratação de servidores técnico-administrativos.

A partir dos dados apresentados, temos um delineamento dos respondentes, que pode expressar um perfil dos técnicos de nível médio que atuam em secretarias na universidade: são igualmente divididos entre os sexos, a maioria acima de 46 anos e com mais de 16 anos de trabalho na universidade, e que, especificamente, atuam há mais de dez anos em funções secretariais.

Na mesma oportunidade, foi solicitado aos respondentes que criassem uma escala de dificuldade entre oito itens apresentados, a fim de determinar quais áreas eram mais problemáticas na rotina desses servidores. Nesta questão foi utilizado o método de escalonamento, pelo qual os respondentes deveriam numerar uma ordem de dificuldade quanto aos assuntos apresentados. Alguns deles afirmaram que isso não refletia exatamente a sua realidade, mas devido às limitações do servidor online do questionário (SurveyMonkey) esse foi o tipo de contagem que mais se adaptou à obtenção das respostas que se esperava. O método atribui uma pontuação a cada questão.

Podemos observar na Figura 4 que a maior dificuldade foi atribuída ao quesito "falta de infraestrutura", com nota 5,76, que foi apontada por $28,57 \%$ dos servidores. Cabe aqui destacar novamente o contexto político de investimentos do governo do Estado do Paraná, que vem, sistematicamente, diminuindo os recursos destinados à construção de blocos e melhoria da infraestrutura da universidade há vários anos, fazendo com que a estrutura disponível seja desgastada pelo uso recorrente, inclusive com diversos blocos, em construção, com as obras paralisadas.

Em segundo lugar foi apontado a dificuldade com "organização de eventos" (nota 5,29). Essa dificuldade pode ser advinda do fato de que são poucos os eventos organizados pelos departamentos a cada ano e que, na 
universidade, não há um setor específico para essa área.

A Divisão de Cerimonial da universidade tem a função de realizar o cerimonial dos eventos da instituição, mediante solicitação do departamento proponente, sendo responsável, somente, por organizar as cerimônias de colação de grau no campus sede e regionais, e tendo servidores atuando como Mestre de Cerimônias em eventos para os quais é requisitado.

Dessa forma, a gestão de eventos diversos fica também a cargo das secretarias de curso, ou seja, dos servidores entrevistados, por fazer parte do escopo administrativo de sua função.

Conforme Schumacher, Portela e Borth (2013), organização de eventos faz parte das atribuições de técnicos de nível de médio em funções de assessoramento.

A seguir, temos nessa ordem de respostas outras dificuldades: "gestão de arquivos físicos e/ou digitais", apontado por $20,24 \%$ dos servidores (nota $5,02)$. Seguindo a escala, da maior dificuldade para a menor temos: "gestão do tempo" (4,99); "redação oficial" $(4,48)$; "atendimento ao público" $(4,02)$; "relacionamento com os colegas" $(3,37)$; e "relacionamento com a chefia" (3.01). Para esta pesquisa, estas dificuldades são todas passíveis de serem melhor trabalhadas com a realização de cursos, que tenham como foco as habilidades secretariais elencadas no referencial teórico.

Figura 4: Escalonamento das dificuldades dos servidores por assunto ${ }^{4}$ 


\section{Escalonamento de dificuldades}

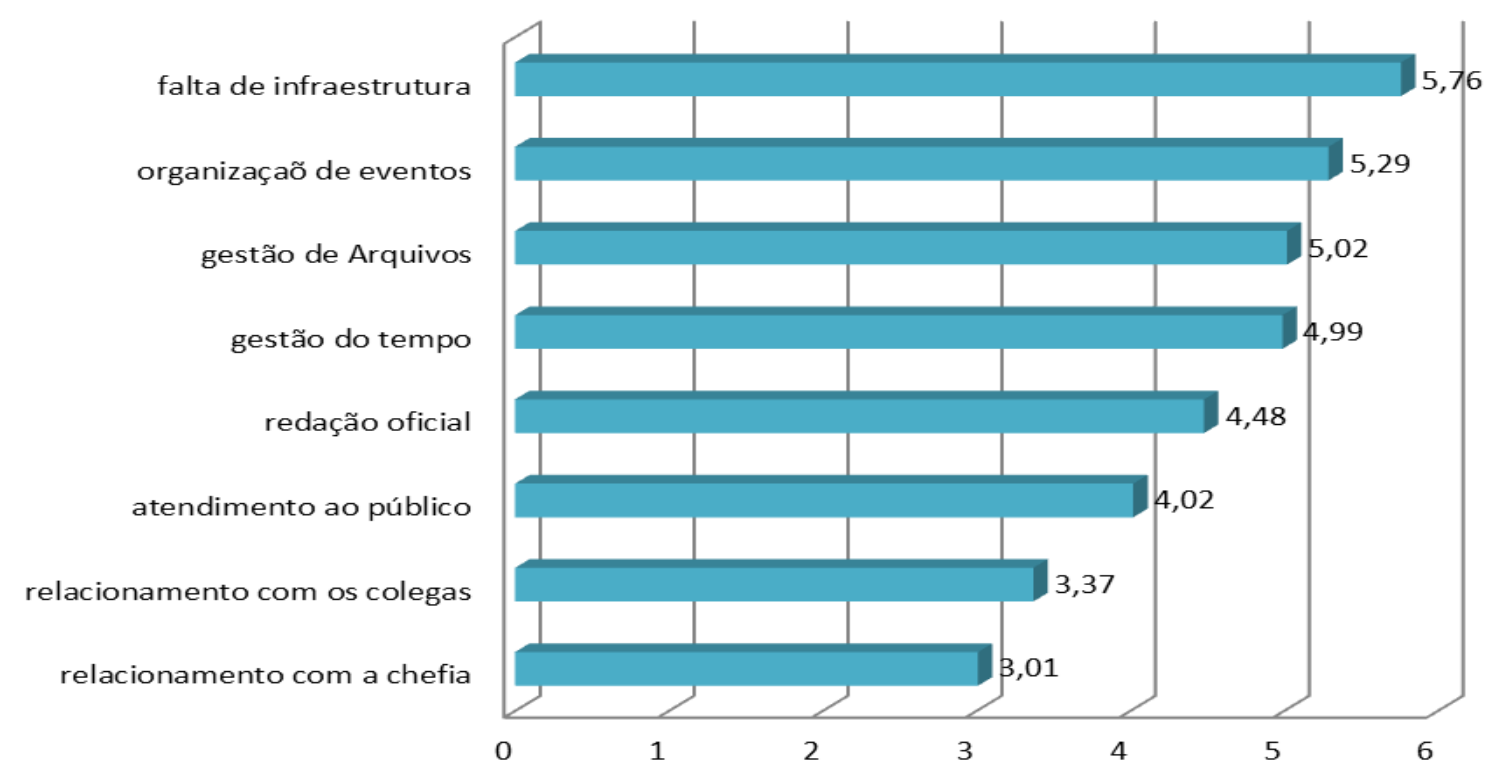

Fonte: Dados da pesquisa.

A Divisão de Treinamento e Desenvolvimento da universidade, objeto da pesquisa, tem oferecido cursos na área de secretariado, que focam o desenvolvimento das habilidades aqui citadas. Entretanto, devido à escassez de recursos financeiros, a quantidade desses treinamentos tem variado bastante.

Segue na Tabela 1, um levantamento dos cursos oferecidos, com enfoque nas habilidades secretariais, nos últimos seis anos:

Tabela 1: Cursos oferecidos pela Divisão de Treinamento e Desenvolvimento da Universidade, com ênfase em habilidades secretariais 


\begin{tabular}{|c|c|}
\hline Ano & Quantidadede cursos \\
\hline 2011 & 3 \\
\hline 2012 & 1 \\
\hline 2013 & 6 \\
\hline 2014 & 3 \\
\hline 2015 & 1 \\
\hline 2016 & 1 \\
\hline
\end{tabular}

Fonte: Elaborada pelas autoras, com base em dados fornecidos pela TDE.

Os cursos oferecidos têm, em sua maioria, enfoque nas relações interpessoais e na resolução de conflitos e no atendimento ao público, com várias turmas ao longo dos anos. Foi ofertado, uma vez nesse período, um curso de comunicação escrita. São ofertados também vários treinamentos para operação de sistemas específicos da universidade, como o de compras, por exemplo.

Além dos cursos realizados pela divisão, são ofertados, também, cursos pela Escola de Governo, os quais não foram apurados para esta pesquisa, visto o foco do estágio ser a identificação das dificuldades para a elaboração de cursos pela pesquisadora servidora da instituição, que poderiam ser ministrados por pessoal disponível na própria universidade.

$\mathrm{Na}$ figura a seguir, temos os dados referentes à motivação para participação nos cursos ofertados pela divisão de treinamento.

Figura 5 - Motivação para participação ou não em cursos oferecidos pela Divisão de Treinamento e Desenvolvimento 
Motivação para participação

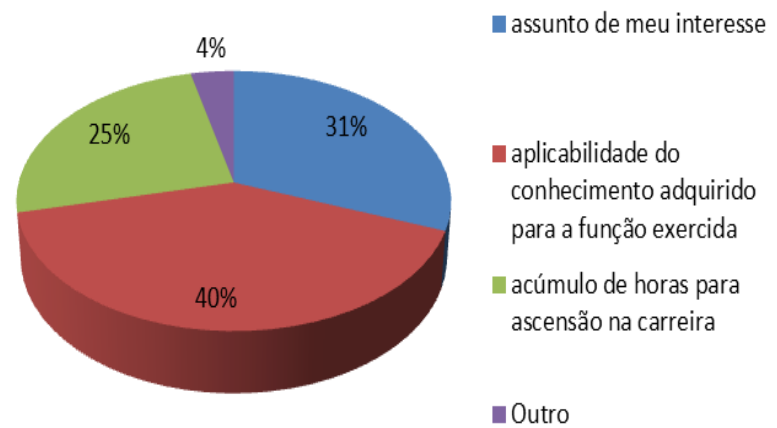

Motivação para não participação

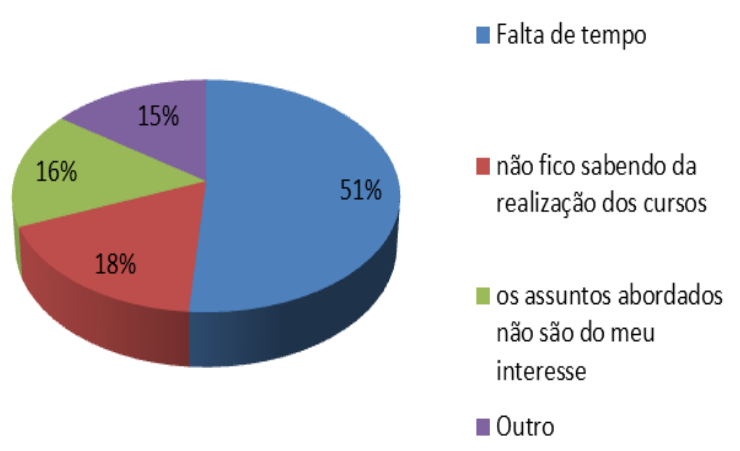

Fonte: Dados da pesquisa.

Para essas questões, era possível assinalar mais de uma resposta. Para a maioria dos respondentes (55 servidores), a "aplicabilidade do conhecimento adquirido para a função exercida" é o determinante no interesse em participação dos cursos oferecidos pela TDE, seguida pelo "assunto ser de seu interesse" e pelo "acúmulo de horas para a progressão na carreira". Para a maioria a "falta de tempo" é o maior empecilho à participação nos cursos, tendo em sequência afirmado não ficar "sabendo da realização deles", ou que "os assuntos não eram do seu interesse".

Entretanto, segundo as funcionárias do setor de treinamento e desenvolvimento, esses dados podem não revelar exatamente a realidade, visto que a maioria dos servidores que procuram a divisão para realizar os cursos explicitarem somente a necessidade de horas para a progredir na carreira.

\section{CONSIDERAÇÕES FINAIS}

A atuação no serviço público é, geralmente, desejada devido à estabilidade e aos salários, geralmente atrativos. A concorrência nos concursos, dependendo do cargo, chega a ser maior que muitos vestibulares. Apesar disso, o serviço público é conhecido como moroso e ineficiente.

Por meio do presente trabalho, buscou-se aplicar o conhecimento adquirido da formação na área secretarial para identificar rotinas 
administrativas passíveis de melhorias, que guardam relação com o perfil profissiográfico de um secretário em formação, a partir de problemas identificados por uma das pesquisadoras que atua como servidora da universidade há 14 anos, instituição tomada como objeto deste estudo.

Apesar de uma amostragem relativamente pequena em comparação ao número de servidores que atuam em funções secretariais na Universidade, mas que representa o universo do objeto pesquisado, pode-se apurar que os dados refletem as impressões observadas, e que há uma necessidade premente por cursos na área secretarial, a fim de desenvolver as habilidades nos servidores, promovendo a eficiência, a eficácia e a efetividade do trabalho.

É perceptível que a formação secretarial, com seus conceitos de gestão e assessoramento, podem contribuir para a atuação de servidores públicos que exercem funções administrativas em secretarias, conforme demonstrado nos conceitos relacionados em nosso referencial teórico. Ou seja, apesar de denominados técnicos administrativos de nível médio, na descrição de ocupação de sua ficha funcional, os conhecimentos requeridos para a função são aqueles da formação em Secretariado. Sendo assim, a necessidade de gestão de pessoal na universidade estudada nesta função retrata a observação de embasamento em conhecimentos ensinados na formação secretarial, e justificam o levantamento de assuntos relacionados com essa formação para a capacitação dos servidores.

Por meio do questionário, foi possível identificar a áreas relacionadas ao secretariado de maior dificuldade por parte dos técnicos administrativos. Tais área citadas são aquelas elencadas dentro do escopo da gestão secretarial, conforme observado na definição do tema por Nonato Junior (2009).

Assim, devido a identificação dessa relação, a aplicação deste estudo, concluiu que a promoção de cursos de curta duração, nos temas levantados, é viável já que há pessoal qualificado junto aos professores de Secretariado para tal fim, pois, no momento não há a possibilidade de contratação de pessoal externo considerando a atual política do governo do Estado do Paraná, no tocante ao sistemático corte de recursos, principalmente aos destinados para treinamento dos servidores. 
Apesar dos dados apurados, ao considerar o cotidiano vivenciado e apresentado pelas servidoras da Divisão de Treinamento e Desenvolvimento, onde foi realizada inicialmente a pesquisa, pode-se inferir que a maior dificuldade apresentada será a mudança da visão dos próprios servidores, que necessitam de capacitação. Ou seja, é necessário que estes entendam a necessidade de se qualificarem visando a melhoria do seu trabalho, percebendo tais deficiências e dificuldades e a semelhança com a formação secretarial, o que promoveria um ganho na eficiência, na eficácia e na efetividade, e não apenas nos ganhos financeiros.

Destacamos ainda que este é um assunto pouco discutido, tornando, portanto, o estudo muito importante para a área e inclusive para a valorização do profissional de secretariado neste segmento, além do mesmo poder contribuir e ser replicado nas várias esferas do serviço público, tanto estadual, como municipal e federal.

Visto este ser um estudo inicial, faz-se necessário aprofundá-lo, seja por meio de uma pesquisa mais abrangente quanto ao número de respondentes, ou optando por entrevistas mais específicas, detalhando-se as peculiaridades de cada setor onde atuam os técnico-administrativos.

\section{REFERÊNCIAS}

AMARAL, Lenita Almeida e LOPES, Silvia Marise Araújo. Rotatividade no Serviço Público Federal: Um estudo de caso na UFPE. In: Congresso de Gestão Pública, VII. Brasília, DF. Anais... Brasília, DF. Banco do Conhecimento CONSAD. 2014. Disponível em:

http://periodicos.ufpb.br/ojs2/index.php/tpa/article/view/12253. Acesso em $31 / 10 / 2016$.

AMORIM, Tania Nobre Gonçalves Ferreira e SILVA, Ladjane de Barros. Treinamento no Serviço Público: Uma abordagem com Servidores TécnicoAdministrativos de Universidade, In: Teoria e Prática da Administração. João Pessoa. v.3, n. 1, 2012.

BERGUE, Sandro Trescastro. Gestão de pessoas em organizações públicas. 2. ed. Caxias do Sul, Educs, 2007. 
BRASIL, PRESIDÊNCIA DA REPÚBLICA (1995). Plano diretor da reforma do aparelho do Estado. Brasília: Câmara da Reforma do Estado. Disponível em: http://www.bresserpereira.org.br/documents/mare/planodiretor/planodiretor.pdf.

Acesso em 05/06/2017.

BRUNELLI, Maria da Graça Mello. Motivação no serviço público. 2008.

Trabalho de Conclusão (MBA em Gestão Pública). Faculdade IBGEN - Instituto Brasileiro de Gestão de Negócios. Porto Alegre, RS. Disponível em:

http://lproweb.procempa.com.br/pmpa/prefpoa/sma/usu doc/maria da graca mello br unelli. tcc.pdf. Acesso em: 31/10/2016.

CHIAVENATTO, Idalberto. Gestão de Pessoas: o novo papel dos recursos humanos nas organizações. Rio de Janeiro: Elsevier, 2004.

FERREIRA, Ademir A.; REIS, Ana C. F.; PEREIRA, Maria I. Gestão Empresarial: de

Taylor aos nossos dias: evolução e tendências da moderna administração de empresas. São Paulo: Pioneira Thomson Learning, 2002.

LESSA, Josiane Kirchener e SCHELL, Marcos Machado. As competências do Profissional de Secretariado e a utilização de Ferramentas de Gestão nas Organizações. In: Modelos de Gestão no Contexto do Profissional de Secretariado. MARTINS, Cibele Marsalini; D'ELIA, Bete (org.). Florianópolis: Departamento de Ciências da Administração.UFSC, 2015.

MOTTA, Paulo Roberto de Mendonça. O Estado da Arte da Gestão Pública. In: Revista Pensata. São Paulo. v. 53, n.1, jan/fev. 2013. p. 82-90. Disponível em: http://rae.fgv.br/sites/rae.fgv.br/files/artigos/10.1590 00347590201300100007.pdf. Acesso em 19-06/2017.

NONATO JUNIOR, R. Epistemologia e Teoria do Conhecimento em Secretariado Executivo: a fundação das ciências da assessoria. Fortaleza: Editora Expressão Gráfica, 2009.

ONU/Departamento de Assuntos Econômicos e Sociais. A Gestão de Pessoas como recurso estratégico. In: Revista do Serviço Público. Brasília, Jul/Set 2006. Disponível em:

http://antigo.enap.gov.br/index.php?option=com docman\&task=cat view\&gid=853. Acesso em: 31/01/2016.

PARANÁ. Resolução Conjunta no 001/2007-SEAP/SETI. Publica os Perfis Profissiográficos das Funções componentes das Classes I, II e III de que trata a 
Lei Estadual n.ำ15.050 de 12 de abril de 2006. Disponível em: http://www.drh.uem.br/res/Resol_conjunta_01_07.pdf.

SEVERINO, Antônio Joaquim. Metodologia do Trabalho Científico. 23. ed. SP: Cortez, 2007.

SILVA, Joelma Soares da; BARROS, Conceição de Maria Pinheiro e BARBOSA, Maria Flaviana Silva. Fundamentação Da Gestão Secretarial:

Um Estudo Bibliométrico. In: Revista de Gestão e Secretariado - GeSec, São Paulo, v. 3, n. 2, p 106-126, jul./dez. 2012. Disponível em:

https://www.revistagesec.org.br/secretariado/article/view/114/pdf_14. Acesso em 01/02/2016.

SCHUMACHER, Alexandre José; PORTELA, Keyla Cristina Almeida; BORTH, Marcelo Rafael. Ferramentas do Secretário executivo. 2.ed. Cuiabá, MT: Dos Autores, 2013.

TERENCE, Ana Claudia Fernandes; ESCRIVÃO FILHO, Edmundo. Abordagem quantitativa, qualitativa e a utilização da pesquisa-ação nos estudos organizacionais. In: Anais do XXXVI Encontro Nacional de Engenharia de Produção. Fortaleza, CE. 2006. Disponível em: http://www.abepro.org.br/biblioteca/enegep2006 tr540368 8017.pdf. Acesso em $\underline{08 / 06 / 2017}$. 


\section{ANEXO 1}

Tabela de escalonamento atribuído pelos respondentes referentes à figura 4.

\begin{tabular}{|c|c|c|c|c|c|c|c|c|c|c|c|}
\hline & $v$ & $\nabla$ & $\nabla$ & 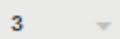 & 4 & v & 6 & 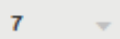 & v & Total = & Pontuaçäo * \\
\hline 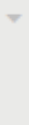 & $\begin{array}{l}\text { Gestão de } \\
\text { arquivos } \\
\text { físicos e/ou } \\
\text { digitais }\end{array}$ & $\begin{array}{r}20,24 \% \\
17\end{array}$ & $\begin{array}{r}10,71 \% \\
9\end{array}$ & $\begin{array}{r}17,86 \% \\
15\end{array}$ & $\begin{array}{r}11,90 \% \\
10\end{array}$ & $\begin{array}{r}9,52 \% \\
8\end{array}$ & $\begin{array}{r}11,90 \% \\
10\end{array}$ & $\begin{array}{r}7,14 \% \\
6\end{array}$ & $\begin{array}{r}10,71 \% \\
9\end{array}$ & 84 & 5,02 \\
\hline v & $\begin{array}{l}\text { gestão do } \\
\text { tempo }\end{array}$ & $\begin{array}{r}5,95 \% \\
5\end{array}$ & $\begin{array}{r}20,24 \% \\
17\end{array}$ & $\begin{array}{r}16,67 \% \\
14\end{array}$ & $\begin{array}{r}20,24 \% \\
17\end{array}$ & $\begin{array}{r}14,29 \% \\
12\end{array}$ & $\begin{array}{r}9,52 \% \\
8\end{array}$ & $\begin{array}{r}9,52 \% \\
8\end{array}$ & $\begin{array}{r}3,57 \% \\
3\end{array}$ & 84 & 4,99 \\
\hline v & $\begin{array}{l}\text { relacionamento } \\
\text { com os } \\
\text { colegas }\end{array}$ & $\begin{array}{r}7,14 \% \\
6\end{array}$ & $\begin{array}{r}4,76 \% \\
4\end{array}$ & $\begin{array}{r}8,33 \% \\
7\end{array}$ & $\begin{array}{r}9,52 \% \\
8\end{array}$ & $\begin{array}{r}11,90 \% \\
10\end{array}$ & $\begin{array}{r}11,90 \% \\
10\end{array}$ & $\begin{array}{r}19,05 \% \\
16\end{array}$ & $\begin{array}{r}27,38 \% \\
23\end{array}$ & 84 & 3,37 \\
\hline v & $\begin{array}{l}\text { relacionamento } \\
\text { com a chefia }\end{array}$ & $\begin{array}{r}2,38 \% \\
2\end{array}$ & $\begin{array}{r}7,14 \% \\
6\end{array}$ & $\begin{array}{r}4,76 \% \\
4\end{array}$ & $\begin{array}{r}5,95 \% \\
5\end{array}$ & $\begin{array}{r}14,29 \% \\
12\end{array}$ & $\begin{array}{r}14,29 \% \\
12\end{array}$ & $\begin{array}{r}22,62 \% \\
19\end{array}$ & $\begin{array}{r}28,57 \% \\
24\end{array}$ & 84 & 3,01 \\
\hline r & $\begin{array}{l}\text { falta de } \\
\text { infraestrutura }\end{array}$ & $\begin{array}{r}28,57 \% \\
24\end{array}$ & $\begin{array}{r}21,43 \% \\
18\end{array}$ & $\begin{array}{r}10,71 \% \\
9\end{array}$ & $\begin{array}{r}9,52 \% \\
8\end{array}$ & $\begin{array}{r}8,33 \% \\
7\end{array}$ & $\begin{array}{r}11,90 \% \\
10\end{array}$ & $\begin{array}{r}7,14 \% \\
6\end{array}$ & $\begin{array}{r}2,38 \% \\
2\end{array}$ & 84 & 5,76 \\
\hline v & $\begin{array}{l}\text { atendimento ao } \\
\text { público } \\
\text { (pessoalmente } \\
\text { e por telefone) }\end{array}$ & $\begin{array}{r}8,33 \% \\
7\end{array}$ & $\begin{array}{r}8,33 \% \\
7\end{array}$ & $\begin{array}{r}10,71 \% \\
9\end{array}$ & $\begin{array}{r}10,71 \% \\
9\end{array}$ & $\begin{array}{r}15,48 \% \\
13\end{array}$ & $\begin{array}{r}17,86 \% \\
15\end{array}$ & $\begin{array}{r}15, \mathbf{4 8} \% \\
13\end{array}$ & $\begin{array}{r}13,10 \% \\
11\end{array}$ & 84 & 4,02 \\
\hline v & $\begin{array}{l}\text { organização de } \\
\text { eventos }\end{array}$ & $\begin{array}{r}8,33 \% \\
7\end{array}$ & $\begin{array}{r}20,24 \% \\
17\end{array}$ & $\begin{array}{r}21,43 \% \\
18\end{array}$ & $\begin{array}{r}21,43 \% \\
18\end{array}$ & $\begin{array}{r}9,52 \% \\
8\end{array}$ & $\begin{array}{r}10,71 \% \\
9\end{array}$ & $\begin{array}{r}5,95 \% \\
5\end{array}$ & $\begin{array}{r}2,38 \% \\
2\end{array}$ & 84 & 5,29 \\
\hline 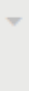 & $\begin{array}{l}\text { redação oficial } \\
\text { (atas, ofícios, } \\
\text { e-mails, etc.) }\end{array}$ & $\begin{array}{r}19,05 \% \\
16\end{array}$ & $\begin{array}{r}7,14 \% \\
6\end{array}$ & $\begin{array}{r}8,33 \% \\
7\end{array}$ & $\begin{array}{r}10,71 \% \\
9\end{array}$ & $\begin{array}{r}16,67 \% \\
14\end{array}$ & $\begin{array}{r}11,90 \% \\
10\end{array}$ & $\begin{array}{r}13,10 \% \\
11\end{array}$ & $\begin{array}{r}13,10 \% \\
11\end{array}$ & 84 & 4,48 \\
\hline
\end{tabular}

